\title{
Effects of Unit-Based Garbage Pricing: A Differences-in-Differences Approach
}

\author{
Maarten A. Allers • Corine Hoeben
}

Accepted: 28 August 2009 / Published online: 19 September 2009

(C) The Author(s) 2009. This article is published with open access at Springerlink.com

\begin{abstract}
Using a unique 10-year dataset of all 458 Dutch municipalities, we apply a differences-in-differences approach to estimate the effect of unit-based pricing on household waste quantities and recycling. Community-level studies of unit-based pricing typically do not include fixed effects at the local level. We find that failure to do so may substantially inflate the estimated price effect. We also find that unit-based pricing may be endogenous, and use instrumental variables to account for this. Our analysis shows that user fees depend on user fees in neighboring jurisdictions (policy interaction). Our estimate of the garbage reduction per $\$ 1$ user fee is lower than any previous estimate bar one. The price effect depends on the pricing system: weight-based systems reduce garbage quantities more than volume-based systems. User fees increase recycling, especially of paper, but not nearly as much as they reduce garbage quantities. We find no evidence for waste tourism or illegal dumping.
\end{abstract}

Keywords Unit-based pricing · Household waste - Recycling · Endogenous policy · Policy interaction

JEL Classification $\mathrm{H} 31 \cdot \mathrm{Q} 53$

\section{Introduction}

Growing quantities of household waste are an increasing problem in many countries. Collecting, transporting and disposing of household waste is costly and creates environmental problems. Since many households pay a flat fee, independent of the amount of waste they discard, this amount is likely to be inefficiently high. Therefore, some authors (e.g., Callan and Thomas 1999; Dijkgraaf and Gradus 2008) advocate unit-based pricing (UBP) programs: billing households according to the weight or volume of their garbage. But whether UBP yields a net gain is a contentious issue. UBP may reduce garbage quantities and increase

M. A. Allers $(\varangle) \cdot$ C. Hoeben

COELO and University of Groningen, PO Box 800, 9700 AV, Groningen, The Netherlands

e-mail: m.a.allers@rug.nl 
recycling, but measuring waste quantities and billing households is costly. Moreover, UBP may encourage illegal dumping, and price differences among jurisdictions may result in garbage tourism. Kinnaman (2006) and Kinnaman (2008) argue that the benefits from UBP are negligible, and that, in the United States at least, costs actually exceed benefits. As many jurisdictions around the world have adopted UBP, and others are contemplating its introduction, this is not merely an academic issue. At the moment, there is simply not enough information about the costs and benefits of UBP to resolve this issue.

This paper focuses on the effects of the unit price (or user fee) on waste disposal. Does UBP reduce waste quantities and increase recycling, and if so, by how much? Although many studies have been carried out to answer this question, none of them is entirely satisfactory from a methodological point of view. This is mostly the result of limited data availability.

Earlier work may be divided into household-level studies (Table 1) and community-level studies (Table 2). The advantage of household-level studies is that they apply to the level at which choices regarding garbage quantities are made. However, all but one of the studies in Table 1 rely on survey data, which suffer from non-response. It is hard to rule out that self-selection occurs, introducing a bias in the sample. For example, well-educated people or people who are more susceptible to environmental policies may be more inclined to participate. Another disadvantage of many household studies is the limited time period under study. Households may need time to adapt to new marginal garbage prices. Moreover, there could well be a seasonal trend in garbage disposal as a result of holidays and temperature differences. Finally, existing household-level studies comprise a small number of jurisdictions which do not appear to be representative, and all but one consider only one type of unit pricing program. Therefore, it is unclear whether the results may be generalized.

An advantage of using community-level instead of household-level data is that communities with UBP may more easily be compared with communities with flat fees. Moreover, different communities may use different UBP programs. Unfortunately, community-level studies usually do not take account of unobservable local characteristics that may influence garbage quantities. The fact that in community A, per capita garbage disposal by households is lower than in community B may be the result of unit-based pricing in A. On the other hand, it may as well be the result of a larger share of babies in B's population (diapers being an important component of household waste), or a larger proportion of houses that have a garden in B (more yard waste). Because of data limitations, it is usually impossible to include all relevant community characteristics in the estimation as control variables. As a consequence, bias occurs when unobserved variables are correlated with both garbage quantities and user fees (Baltagi 2005). In order to avoid this problem, a differences-in-differences approach may be used. This can be done by using panel data and including both fixed effects at the community level and time effects. By using fixed effects, the effect of any time-invariant omitted variables is controlled for. Jenkins (1993) is the only community-level study we are aware of that includes fixed effects at the community level, but this study omits time effects. Three other community-level studies to date use panel data (Van Houtven and Morris 1999; Dijkgraaf and Gradus 2004, 2009), but neither of these applies fixed effects at the community level (Table 2). Dijkgraaf and Gradus (2004) and Dijkgraaf and Gradus (2009) do include fixed effects, but at the province level. Our results suggest that these do not capture fixed characteristics at the municipal level.

A second drawback of most community-level studies is that they do not take into account that the garbage price may well be endogenous. It is entirely possible, e.g., that municipalities with high waste quantities are more likely to introduce UBP, because they have more to gain. Or perhaps UBP occurs only in communities where this system may be expected to work well. If the price is endogenous, communities with and without UBP cannot be compared 


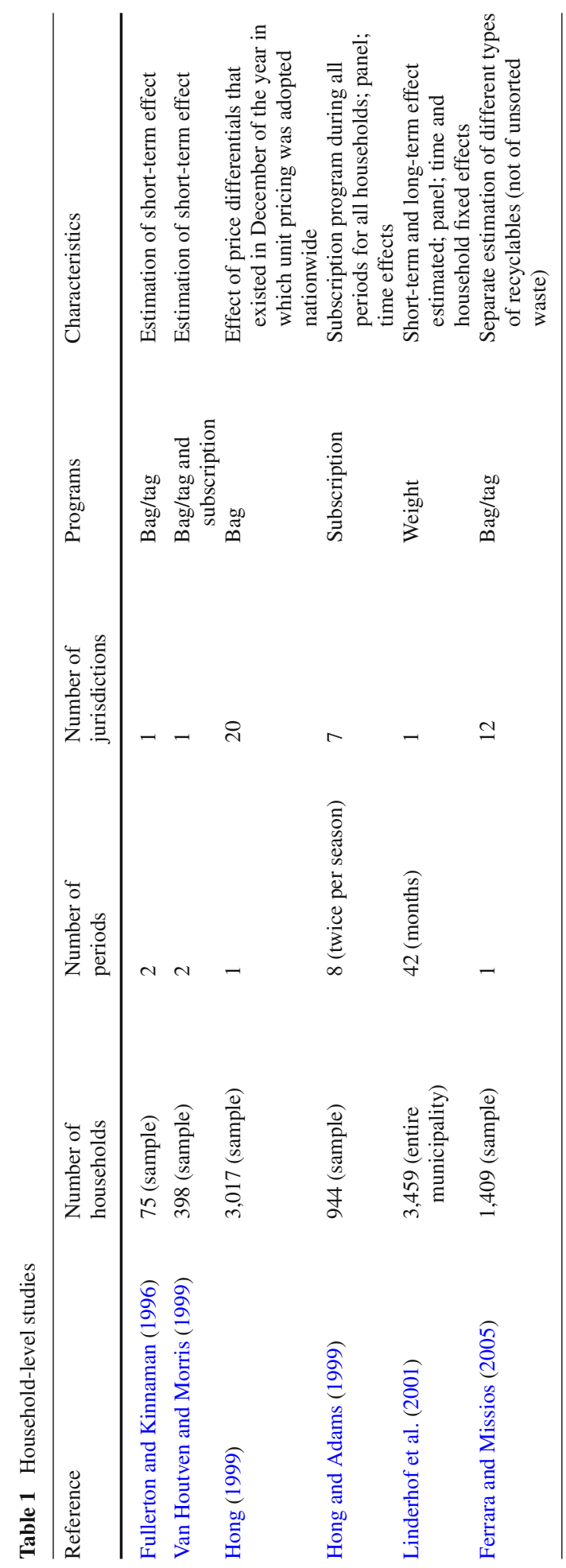




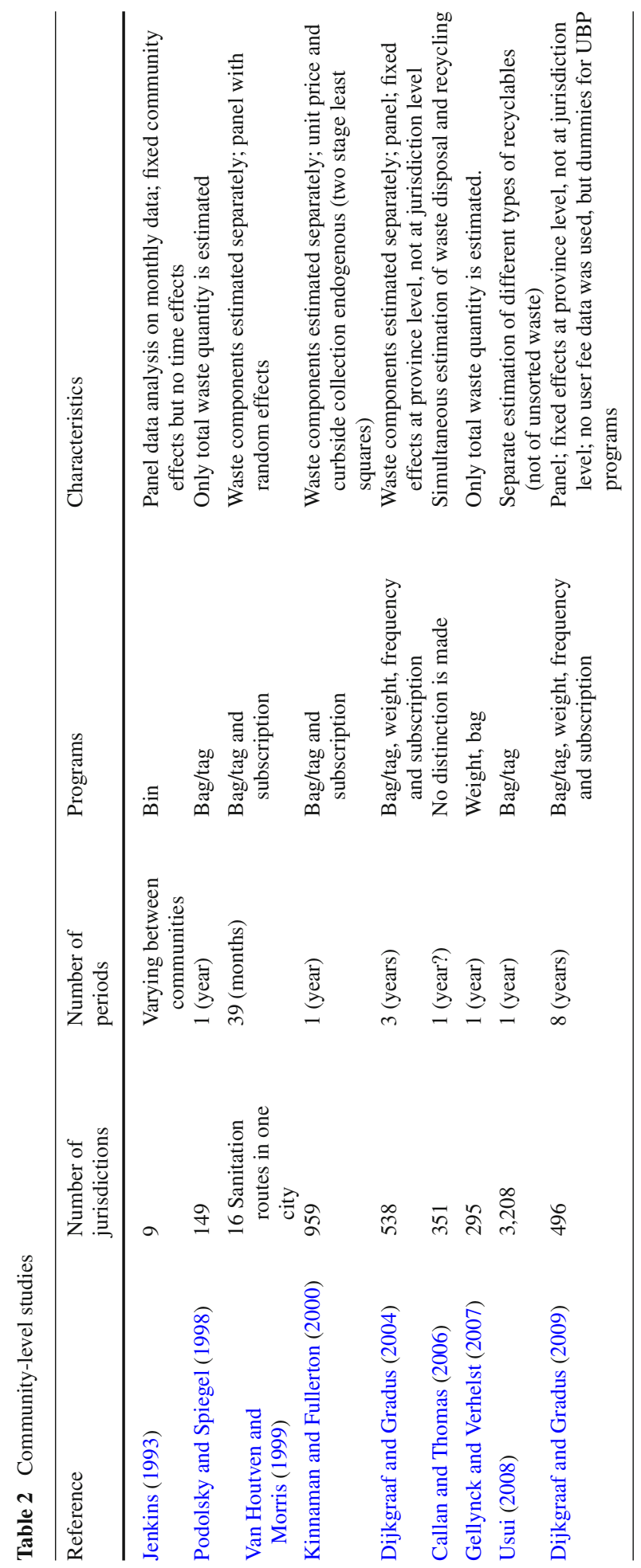


directly. There is no natural experiment (Besley and Case 2000). Kinnaman and Fullerton (2000) correct for endogenous policy using instrumental variables, and find that their results depend crucially on this correction. Dijkgraaf and Gradus (2004) and Dijkgraaf and Gradus (2009) try correcting for environmental activism by testing whether communities that introduce UBP already have lower waste quantities before introduction. Other community-level studies ignore the endogeneity problem.

Just like household-level studies, existing community-level studies sometimes seem to consider only those jurisdictions for which data happen to be available (e.g., Jenkins 1993; Kinnaman and Fullerton 2000), which raises the question of representativeness. Moreover, the time period under study tends to be rather short.

To the best of our knowledge, this paper is the first community-level study of the effect of UBP that applies a differences-in-differences approach. We control for national trends and for unobservable time-invariant local characteristics that may influence garbage quantities by including both time effects and community fixed effects. We also test for endogenous pricing of garbage, and instrument the unit price of garbage if necessary. By avoiding the pitfalls of the community-level approach, we can exploit its advantages. Since we collected community-level data of all municipalities in the Netherlands for a 10-year period (longer than any previous study), we are able to compare communities with and without UBP, and communities with different UBP programs and different unit prices. The time period is long enough to capture long-term effects of pricing on garbage quantities. Most municipalities presently using UBP started doing this during the period we study. Moreover, this period covers many changes in user fees. This gives us the variation we need to carry out a differences-in-differences analysis. We find that user fees do reduce garbage quantities, but not as much as most previous studies suggest. In fact, our estimate of the garbage reduction per $\$ 1$ user fee is lower than any previous estimate bar one.

The rest of this paper is organized as follows. First, we model household demand for garbage disposal. Then, we describe our data and our estimation strategy, and we assess price endogeneity. We continue by presenting our basic results, and a sensitivity analysis. We then consider the effects of different unit-based pricing systems, the possible behavioral responses of households facing user fees, including recycling, and the welfare gains associated with UBP. Finally, we summarize our conclusions.

\section{The Demand for Garbage Disposal}

In the Netherlands, municipalities are responsible for collecting household waste. ${ }^{1}$ They can either collect it themselves or contract a private firm. All municipalities are required by law to collect biodegradable waste (yard waste, discarded food, etc.) and unsorted waste (non-biodegradable, but partly recyclable $)^{2}$ at the curbside separately. ${ }^{3}$ Additionally, they must ensure a sufficient number of drop-off facilities for recyclable waste (glass, paper, textiles). Many municipalities have a long tradition of curbside collection of paper or textiles by charities or sport clubs. There is no charge for disposing of recyclable waste at drop-off facilities or at the curbside.

\footnotetext{
1 The territory of the Netherlands is divided into 458 (2006) jurisdictions run by local governments. These are called gemeenten. We use the term municipalities.

2 Unsorted waste contains, e.g., metals (cans, etc.), which can be extracted before incineration.

3 Some municipalities do not collect unsorted and biodegradable waste separately in inner cities, because the biodegradable waste collected there is mixed with too much non-biodegradable waste to be composted.
} 
Our conceptual framework follows the literature, in particular Kinnaman and Fullerton (2000). Garbage is disposed of in one of the following ways:

- it is presented at the curbside as unsorted waste (quantity $u w$ );

- it is presented at the curbside as biodegradable waste (quantity $b w$ );

- it is presented at the curbside as recyclable waste or discarded at a drop-off facility for recyclable waste (quantity $r w$ );

- it is disposed of in another way, e.g., home composting, illegal dumping, or burning (quantity $o w$ ).

The demand for each disposal manner depends on its price, on the prices of the alternative disposal methods, and on household characteristics $d$.

The price of waste disposal as unsorted or biodegradable waste encompasses the unit price set by the municipality $\left(P_{u}\right.$ or $\left.P_{b}\right)$, and the time and effort associated with disposing waste in this particular manner, which are assumed to depend on household characteristics $d$. The short-term impact of a unit price may differ from the long-term effect. It is conceivable that the introduction of UBP creates a temporary price awareness since it is often accompanied by a media campaign to inform citizens of the new system. This campaign might have a separate effect on garbage quantities, independent of the new pricing system, by making people aware of the garbage they produce (and the desirability to reduce that quantity). ${ }^{4}$ To capture this, we include dummy variables $F_{u}$ and $F_{b}$ which take the value one in the year user fees are introduced for unsorted waste and biodegradable waste, respectively.

The price of recycling includes the extra effort needed to separate different types of waste, and to drop it off at the designated locations. This effort is taken to depend on household characteristics $d$ and on local recycling programs $R$ (e.g., curbside collection of paper). The price of other fashions of waste disposal is assumed to depend on $d$ and on opportunity $O . O$ includes, e.g., the availability of sites where waste can safely be dumped illegally, and of gardens spacious enough to accommodate a compost vat.

The above results in the following system of demand equations:

$$
\begin{aligned}
u w & =u w\left(P_{u}, P_{b}, F_{u}, F_{b}, d, R, O\right) \\
b w & =b w\left(P_{u}, P_{b}, F_{u}, F_{b}, d, R, O\right) \\
r w & =r w\left(P_{u}, P_{b}, F_{u}, F_{b}, d, R, O\right) \\
o w & =o w\left(P_{u}, P_{b}, F_{u}, F_{b}, d, R, O\right)
\end{aligned}
$$

The equations in (1) are simultaneously determined, but as the independent variables they include are identical, they may be estimated separately without introducing a bias. Since $o w$ is not observed, we cannot estimate (1d).

Based on (1), we estimate reduced-form equations for different types of household waste of the following specification:

$$
Q_{i t}=\alpha_{0 i}+\alpha_{1 t}+\alpha_{2} P_{\text {uit }}+\alpha_{3} P_{\text {bit }}+\alpha_{4} F_{\text {uit }} P_{\text {uit }}+\alpha_{5} F_{\text {bit }} P_{\text {bit }}+\alpha_{6} X_{i t}+\varepsilon_{i t}
$$

Here, $Q_{i t}$ is the per capita quantity of unsorted, biodegradable or recyclable waste collected in municipality $i$ in year $t$ (in kilograms); $\alpha_{0 i}$ and $\alpha_{1 t}$ are fixed municipality and year effects; $P_{\text {uit }}$ and $P_{\text {bit }}$ are the unit prices of unsorted and biodegradable waste, respectively (euros per kilogram; zero without UBP); $F_{\text {uit }}$ and $F_{\text {bit }}$ are indicator variables taking the value of one in the year user fees for unsorted or biodegradable waste are introduced; $X_{i t}$ is a vector

4 On the other hand, households may need time to adapt their waste quantities to unit-based prices, in which case the long-term effect exceeds the short-term effect. 
of time-varying municipal characteristics; $\varepsilon_{i t}$ is an error term and $\alpha_{2}, \alpha_{3}, \alpha_{4}, \alpha_{5}$ and $\alpha_{6}$ are parameters to be estimated.

We do not have data on local recycling programs $R$. These change very infrequently, and depend heavily on local socio-demographic characteristics (influencing the presence of sport clubs or charitable organizations which collect paper or textiles). Any remaining effects will largely be captured by the fixed effects and by $X_{i t}$. Moreover, Dijkgraaf and Gradus (2009) show that there is no correlation between recycling programs and the use of unit-based pricing in the Netherlands. Therefore, our results will not be biased by omission of this variable.

Household characteristics $d$ and opportunity $O$ are included partly in $X_{i t}$ and partly in the fixed effects. Since we use municipal fixed effects, we only include variables in $X_{i t}$ which show sufficient variation over time. $X_{i t}$ includes density, average household size, percentage of ethnic minorities, percentage of elderly (aged 65 or more), percentage of children of diaper age (aged 3 or less) and number of inhabitants. Average household income is not included because consistent data are not available for the period under study. This variable changes only gradually. Differences in income between municipalities are controlled for by the fixed effects.

\section{Data}

The absence of studies covering more than a few years may well be due to the difficulty in collecting data on user fees in previous years. Often, memories are short and archives inaccessible or non-existent. We started collecting our data in 1998 and continued up to 2006. Every year, we conducted a survey of all municipalities to collect data on local tax systems and tax rates, including garbage disposal fees. In our survey, data collected the previous year was used to check answers for plausibility. This proved very useful, because tax rates or pricing programs do not usually change much on a yearly basis. All program changes and all price changes above a certain threshold were checked, revealing a considerable number of errors or program subtleties. For example, if asked once, an official may answer that the fee is so much per bin put at the curb. Over the course of a few years, however, we might learn that the first $x$ bins are actually collected without charge. Every year, we continued contacting municipalities until the response rate was $100 \% .^{5}$

In most municipalities, waste fees depend on household size. The next most popular pricing program is a fixed cost per household. These are both flat fees, in the sense that the price is independent of garbage quantities: the unit price is zero. In the Netherlands, there are four distinct UBP programs. Most common, for both unsorted and biodegradable waste, is the bin system, where residents pay a fee for every time their container is emptied at the curbside. The fee may depend on bin size and waste type. In 1997, nine municipalities used a bin system, for both unsorted and for biodegradable waste. In 2006, this number had increased to 62 for unsorted waste and 69 for biodegradable waste respectively. A related volume-based program is the bag program, where residents buy special bags or labels to put on their own bags. For biodegradable waste, the bag system was used in nine municipalities in 1997, and only in five in 2006. For unsorted waste, the bag system was used in 20 municipalities in both 1997 and 2006, with a peak in 2000 (24 municipalities). The use of weight-based systems has doubled since 1997, from 9 to 20 municipalities for both waste types. Municipalities with a weight-based system use garbage trucks which automatically weigh every container

5 Separately from this annual questionnaire, we also collected garbage price data for 1997 . Since we did this retrospectively, we were unable to reliably identify user fees for two municipalities. 
before and after emptying. Finally, a few municipalities (6 in 2006) use a combination of the weight and the bin systems. Here, residents are billed for every time their bin is emptied, but also for the weight of their garbage.

Some municipalities (19 in 1997; 32 in 2006) use a subscription program, where residents are billed according to the bin size they choose, but not according to the number of times their bin is emptied. In principle, the fee is related to the maximum amount of garbage a household can discard, but households are pre-committed to a volume and are charged regardless of actual waste quantities. Thus, in most cases, the costs of a marginal increase in garbage will actually be zero under this system. We therefore do not consider subscription systems to be true UBP systems, and exclude this group from our main analysis. We will check, however, if inclusion would affect our results. To do so, we have to decide what user fee to attach to subscription systems. Previous studies of subscription systems (see Tables 1, 2) have taken the marginal fee for using a larger bin (or an extra bin). We have seen, however, that for many households the cost of a marginal increase in garbage will actually be zero. We will consider both options.

In order to arrive at comparable prices, we convert prices per liter to prices per kilogram. Since households facing a volume-based price for waste are likely to compress their garbage (an effect known in the literature as the "Seattle stomp"), we cannot use aggregate data on garbage weight and volume to convert liters into kilograms, as these are based on both municipalities with and without volume-based pricing. Instead, our conversion rates are based on a survey ${ }^{6}$ of volume-based pricing municipalities, which indicate that, on average, $1 \mathrm{~kg}$ equals 7.51 of unsorted waste or 3.81 of recyclable waste. ${ }^{7}$ In order to test the robustness of our results, we will conduct a sensitivity analysis using different assumptions concerning the number of liters per kilo of garbage (Table 7 below). Another assumption we must make results from the fact that in a number of municipalities, the unit price for emptying the first $x$ bins is zero. Here, $x$ is in the range [5,26], but in more than half of the cases $x$ equals 18 per year. For some households, this will effectively mean a unit price of zero, while the others face a positive unit price. In our main analysis, we will simply ignore this phenomenon, and assume every household to place more than $x$ bins at the curbside. We then conduct a sensitivity test to examine whether our results change when the unit price is set to zero for municipalities where $x \geq 18$ (Table 7).

Prices have been corrected for inflation using the consumer price index. The variation in user fees is considerable. Table 3 shows that user fees are in the range [0.01, 0.47] for unsorted waste and in the range [0.01, 0.31] for biodegradable waste. On average, fees are lowest in municipalities with a bag system.

Figure 1 graphically describes the pattern of UBP introduction. To conserve space, we only show the situation in 1997 and in 2006. From the Figure it is obvious that both UBP and particular UBP programs are geographically clustered. In fact, there seems to have been an "ink spot effect", where a municipality that has introduced user fees often becomes the center from which UBP gradually spreads like a blot of ink on paper.

\footnotetext{
6 Ten municipalities were able to supply the relevant information. The answers we received were in the range $[5.5,10.1]$ kilos per liter for unsorted waste (average 7.47 ), and $[3.2,4.7]$ liters per kilo for recyclable waste (average 3.78).

7 Dijkgraaf and Gradus (2004) make the assumption (not based on empirical evidence) that $1 \mathrm{~kg}$ equals 51 for both biodegradable and unsorted waste. Some other studies (Callan and Thomas 2006; Podolsky and Spiegel 1998; Van Houtven and Morris 1999) also make converting assumptions, but these apply to the United States, where different weight/volume ratios may apply.
} 
Table 3 Summary statistics

\begin{tabular}{llll}
\hline & Weighted mean & Minimum & Maximum \\
\hline Unsorted waste (kg per inhabitant per year) & 243 & 68 & 914 \\
Biodegradable waste (kg per inhabitant per year) & 87 & 1 & 360 \\
Recycled waste (kg per inhabitant per year) & 87 & 19 & 287 \\
Unit price unsorted waste (euro/kg) & & & \\
All municipalities & 0.03 & 0 & 0.47 \\
Municipalities with UBP & 0.18 & 0.01 & 0.47 \\
Municipalities with weight system & 0.19 & 0.05 & 0.31 \\
Municipalities with bag system & 0.13 & 0.02 & 0.21 \\
Municipalities with bin system & 0.20 & 0.01 & 0.47 \\
Municipalities with combination weight/bin & 0.20 & 0.15 & 0.23 \\
Unit price biodegradable waste (euro/kg) & & & \\
All municipalities & 0.01 & 0 & 0.31 \\
Municipalities with UBP & 0.12 & 0.01 & 0.31 \\
Municipalities with weight system & 0.19 & 0.05 & 0.31 \\
Municipalities with bag system & 0.07 & 0.02 & 0.13 \\
Municipalities with bin system & 0.10 & 0.01 & 0.24 \\
Municipalities with combination weight/bin & 0.21 & 0.17 & 0.24 \\
Density (addresses/km ${ }^{2}$ ) & 1,728 & 105 & 6,115 \\
Average household size & 2.32 & 1.70 & 3.72 \\
Percentage of ethnic minorities & 9.5 & 0.3 & 35.4 \\
Percentage of elderly (65 and over) & 13.7 & 6.4 & 27.8 \\
Percentage of babies (aged 3 or less) & 5.0 & 2.8 & 9.4 \\
Number of inhabitants & 126,620 & 986 & 743,079 \\
Ideology (percentage share of right-wing parties) & 44.5 & 0 & 94.7 \\
\hline
\end{tabular}

Note: In the period under study, the value of one euro in US dollars was in the range $[0.9,1.26]$

Our unique 10-year garbage pricing dataset was combined with annual data from Statistics Netherlands on per capita household garbage weight per municipality and on municipal characteristics (Table 3). ${ }^{8}$ Data on garbage weights are unlikely to contain many measurement errors, as municipalities, which supply this information to Statistics Netherlands, pay waste treatment companies according to the weight of their garbage. Statistics Netherlands carries out a number of checks on the data as well. The data include household garbage collected at the curbside (by the municipality, a private contractor, or, e.g., a sport club) and at drop-off facilities. Data on garbage quantities is missing in some cases. Thus, we have an unbalanced panel.

In the period under study, some municipalities have been merged or amalgamated. We combined the data for these municipalities by calculating weighted averages for prices and waste quantities. Our population consists of all 458 municipalities that existed in 2006.

8 Available from Statistics Netherlands (http://statline.cbs.nl/StatWeb/?LA=en). 

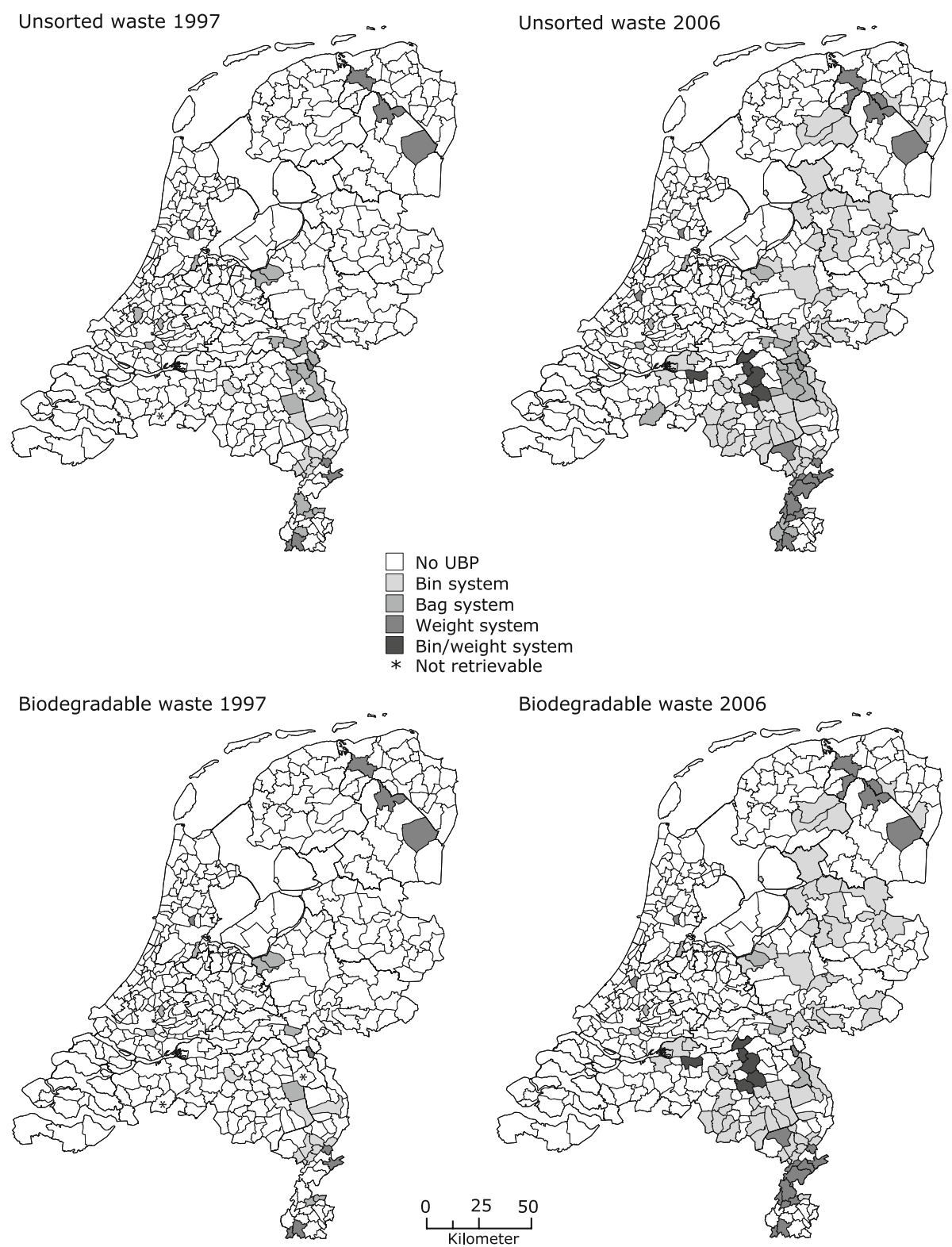

Fig. 1 UBP programs in 1997 and 2006

\section{Estimation Strategy}

As indicated, $P\left(P_{\text {uit }}\right.$ and $P_{\text {bit }}$ in (2)) may well be endogenous. Thus, before we can analyze the effect of unit fees on garbage quantities, we must analyze what determines user fees, in order to find out whether we have to control for endogeneity.

$P$ may be endogenous for different reasons. In the first place, some municipalities may be more likely to apply a UBP program than others. For example, localities with large per capita 
waste quantities may want to use UBP because the potential benefits of waste reductions are larger. Using municipal fixed effects does of course mitigate this policy endogeneity problem, but it may not be sufficient if there are time-varying, municipality-specific trends.

In order to assess endogeneity, we need suitable instruments (Besley and Case 2000): variables that influence $P$ but not $Q$. Callan and Thomas (1999) identify a number of characteristics that may influence UBP adoption, but these are either time-invariant or likely to affect garbage quantities. A look at the map (Fig. 1) suggests that garbage pricing policies of individual municipalities may well depend on policies in nearby jurisdictions. Policy interaction among jurisdictions is a well established phenomenon (Brueckner 2003). Several studies found that the introduction of a tax is more likely if neighboring jurisdictions have already introduced such a tax (Ashworth et al. 2006; Berry and Berry 1992). Policy interaction in waste pricing may be the result of political yardstick competition (as suggested by Heijnen 2007) or information dissemination. Political yardstick competition is the phenomenon whereby voters use the performance of nearby jurisdictions as a benchmark to assess their own administrators (Salmon 1987). This may result in copycatting: jurisdictions mimicking their neighbors' policies. Information dissemination may result in a similar effect, because introducing a user fee is risky. Politicians may be reluctant to adopt UBP because they fear problems, e.g., related to illegal dumping. If neighboring jurisdictions have introduced UBP without encountering such problems, the likelihood of a municipality introducing UBP itself may well be higher. Apart from tax adoption, tax rates have been found to depend on tax rates in neighboring jurisdictions; see Allers and Elhorst (2005) for an overview of empirical studies. If policy interaction is driven by information dissemination or political yardstick competition, there is no reason to assume that price in neighboring municipalities is likely to have an independent effect on $Q$.

Alternatively, however, policy interaction may be driven by negative externalities. High prices in neighboring jurisdictions may cause an influx of waste (waste tourism), which in turn could compel municipalities to introduce UBP themselves. If this is the case, the price in neighboring jurisdictions is obviously not a valid instrument, because it has an independent influence on garbage quantity. Dijkgraaf and Gradus (2004) found no evidence of waste tourism in the Netherlands, but, as we have argued, their results may be compromised because they do not use fixed effects at the local level. ${ }^{9}$ A priori, the fact that not only user fees, but also the type of UBP (weight, bag, bin, or both weight and bin) is clustered geographically (Fig. 1), seems to lend more support to the yardstick competition or the information dissemination hypothesis than to that of garbage tourism.

A second potentially valid instrument is ideology, or the political color of the municipal council. Some parties may favor pay-as-you-throw for political reasons, while others may be more concerned by the ability of large families to pay garbage fees. Because fees are set by the municipal council in the preceding year, we use the political color of the council in $t-1$ (operationalized as the share of right-wing parties). We will discuss the validity of both instruments in the next section.

Following Kinnaman and Fullerton (2000), we assume that municipalities trade off benefits and costs to determine the optimal price. A high price may reduce the amount of garbage put at the curbside, but if they are to reduce their garbage quantity, citizens incur costs associated with better recycling, home composting, etc. Moreover, a high price may also encourage illegal dumping. The optimal price is given by:

$$
P_{i t}^{*}=\beta_{0 i}+\beta_{1 t}+\beta_{2} \mathrm{WP}_{i t-1}+\beta_{3} I_{i t}+\beta_{4} X_{i t}+\phi_{i t} .
$$

9 Moreover, their estimates are based on user fee data for 2003 only, which was used as a proxy for actual user fees in 1998-2000. 
Here, $\beta_{0 i}$ and $\beta_{1 t}$ are fixed municipality and year effects; $W$ is a spatial weights matrix describing the spatial relationship between municipalities; $I_{i t}$ reflects ideology; $\phi_{i t}$ is an error term and $\beta_{2}, \beta_{3}$ and $\beta_{4}$ are parameters to be estimated. For $W$ we use a row-normalized contiguity matrix. Thus, $\mathrm{WP}_{i t-1}$ is the average garbage price in adjacent municipalities in the previous year. ${ }^{10}$ We use the price in the previous year because the effects of UBP will only become clear gradually, and because it takes time to change the price of waste, especially if a UBP program is introduced. Moreover, using a time lag removes the simultaneity that would exist if prices were modeled to depend on contemporaneous prices in neighboring jurisdictions (see, e.g., Rincke 2007).

While the optimal price $P^{*}$ given by (3) may be negative, the actual price $P$ must be either positive (UBP) or zero (flat fee):

$$
P_{i t}=\max \left(0, P_{i t}^{*}\right)
$$

We estimate (3) and (4) using a Tobit model. It is well known that the maximum likelihood estimator is biased and inconsistent in nonlinear panel data models with fixed effects in case the number of time periods is small. ${ }^{11}$ However, in the case of the Tobit model, this estimator is only slightly affected by the incidental parameters problem (Greene 2003). The standard errors are biased downwards, making inference more difficult, but the point estimates can be used to construct an instrument for $P$.

In the next step, we use predicted prices calculated from (4) to replace $P_{i t}$ and estimate (2). By comparing this IV estimate with the corresponding OLS estimate, we assess whether garbage fees are in fact endogenous.

Two final comments are in order. First, since we apply fixed effects/differences-in-differences estimation, conventional standard errors may be understated considerably as a result of serial correlation (Bertrand et al. 2004). We therefore report $t$-values based on robust standard errors clustered by municipality, which are typically larger than uncorrected standard errors. Second, since garbage quantities are the result of choices made by individuals or households, we conduct weighted regressions for garbage quantities, using number of inhabitants as weights. ${ }^{12}$

\section{Assessing Price Endogeneity}

Table 4 contains the results of the first stage regressions of $P_{i t} \cdot{ }^{13}$ We report both OLS and Tobit estimates. Recall that the standard errors in the Tobit estimation are likely to be underestimated (and $t$-values overestimated). The coefficient of lagged unsorted waste tariffs in neighboring municipalities is 0.53 when estimated by OLS and 0.44 when the Tobit model is used. This indicates a strong effect within the viable range of

10 In our sensitivity analysis (Table 7), we also use a spatial weight matrix based on distance.

11 As we use population data, not sample data, using random effects instead of fixed effects would be inappropriate.

12 As weights we use the number of inhabitants per municipality in 2002. As part of our sensitivity analysis, we also estimated the model using household weights, and without using weights (see Table 7). Note that the first stage regression is unweighted, as the unit price is determined by municipal councils, not citizens.

13 To conserve space, we do not report the coefficients of the control variables nor the municipal nor time fixed effects. Since we include fixed effects, and since the control variables do not vary very much from one year to the next, the influence of the control variables is limited. Multicollinearity between some of these variables, e.g., percentage of ethnic minorities and number of inhabitants, further reduces their informative value. They are included exclusively to control for any time variant local characteristics, not to assess their effect on garbage quantities. 
Table 4 First stage regression results

\begin{tabular}{|c|c|c|c|}
\hline & Unsorted waste & Biodegradable waste & Biodegradable waste \\
\hline \multicolumn{4}{|l|}{$O L S$} \\
\hline $\mathrm{WP}_{i t-1}$ & $0.53(8.0)$ & $0.55(7.1)$ & $0.55(7.2)$ \\
\hline Ideology & $0.0006(2.4)$ & $0.0003(1.9)$ & \\
\hline $\begin{array}{l}F \text {-statistic of joint } \\
\text { significance of } \mathrm{WP}_{i t-1} \\
\text { and (if included) ideology }\end{array}$ & 33 & 26 & 51 \\
\hline Adj. $R^{2}$ & 0.87 & 0.85 & 0.85 \\
\hline Number of observations & 3,879 & 3,879 & 3,879 \\
\hline \multicolumn{4}{|l|}{ Tobit } \\
\hline $\mathrm{WP}_{i t-1}$ & $0.44(5.8)$ & $0.47(5.4)$ & $0.47(5.4)$ \\
\hline Ideology & $0.0020(4.6)$ & $0.0010(2.5)$ & \\
\hline $\begin{array}{l}F \text {-statistic of joint } \\
\text { significance of } \mathrm{WP}_{i t-1} \\
\text { and (if included) ideology }\end{array}$ & 27 & 18 & 29 \\
\hline Pseudo $R^{2}$ & 0.76 & 0.69 & 0.71 \\
\hline Number of observations & 3,879 & 3,879 & 3,879 \\
\hline
\end{tabular}

Dependent variable: $P_{i t}$ (euro/kg). Municipal characteristics (see text) and municipal and year fixed effects included; $t$-values in parentheses. $\mathrm{WP}_{i t-1}$ is the average user fee in neighboring municipalities in $t-1$

$(-1,1),{ }^{14}$ which is in line with effects found in previous studies of tax interaction. ${ }^{15}$ Both the OLS $t$-value and the (admittedly biased) Tobit $t$-value suggest that the coefficient is strongly significant. The coefficient of ideology is 0.0006 in the OLS estimate and 0.0020 in the Tobit estimation. According to the presented $t$-values, the ideology-effect is significant.

For biodegradable waste, the coefficient of lagged neighboring waste tariffs is similar to that for unsorted waste: 0.55 according to the OLS-estimate, 0.47 according to the Tobit estimate. The political color of the local council, on the other hand, seems to have less of an effect on tariffs for biodegradable waste than on those for unsorted waste.

Table 5 shows results from our waste estimations based on (2). We start with simplified versions of (2), excluding the unit price of biodegradable waste in the unsorted waste regression, and vice versa, and excluding dummies for the first year UBP is used ( $F_{\text {uit }}$ and $\left.F_{\text {bit }}\right)$. Column 1 reports OLS estimates, according to which the waste price has a strong and significant effect on waste quantities. Column 2 contains IV estimates, using the fitted values of the first stage Tobit estimation instead of the actual waste price. ${ }^{16}$ For unsorted waste, the difference between the OLS and the IV estimate is rather small. A Davidson-MacKinnon test for consistency of OLS does not reject the use of OLS for unsorted waste (Davidson and MacKinnon 1993). ${ }^{17}$ The test result indicates that the OLS estimate yields consistent

\footnotetext{
14 We also estimated the Tobit model without municipal specific effects. In this case, the coefficient of lagged unsorted waste tariffs in neighboring municipalities is larger than one (2.2). This would imply that there is no equilibrium, and that unit prices explode. This is not what we observe in practice.

15 Allers and Elhorst (2005) list a number of previous studies which report interaction effects in the range $[0.2,0.6]$.

16 Standard errors are corrected for the fact that we use predicted, not actual prices.

17 This test is similar to the (Durbin-Wu-)Hausman test. Unlike the Hausman test, it will always yield a computable test statistic.
} 
Table 5 Testing for endogeneity

\begin{tabular}{|c|c|c|c|}
\hline & $\begin{array}{l}1 \\
\text { OLS }\end{array}$ & $\begin{array}{l}2 \\
\text { IV }\end{array}$ & $\begin{array}{l}3 \\
\text { IV }\end{array}$ \\
\hline $\mathrm{WP}_{i t-1}$ as instrument & No & Yes & Yes \\
\hline Ideology as instrument & No & Yes & No \\
\hline \multicolumn{4}{|l|}{ Unsorted waste } \\
\hline$P_{i t}$ & $-262(-11.1)$ & $-249(-6.6)$ & \\
\hline Adj. $R^{2}$ & 0.93 & 0.93 & \\
\hline $\begin{array}{l}\text { Davidson-MacKinnon test of OLS } \\
\text { consistency ( } p \text { value) }\end{array}$ & & $0.83(0.36)$ & \\
\hline $\begin{array}{l}F \text {-test of joint significance of fixed effects } \\
\quad(p \text { value })\end{array}$ & $11,846(0.0000)$ & $11,845(0.0000)$ & \\
\hline HRW likelihood test ( $p$ value) & & $5.17(0.02)$ & \\
\hline$J$-test ( $p$ value) & & $1.64(0.20)$ & \\
\hline Number of observations & 3,590 & 3,590 & \\
\hline \multicolumn{4}{|l|}{ Biodegradable waste } \\
\hline$P_{i t}$ & $-385(-13.3)$ & $-462(-9.3)$ & $-463(-9.2)$ \\
\hline Adj. $R^{2}$ & 0.96 & 0.96 & 0.96 \\
\hline $\begin{array}{l}\text { Davidson-MacKinnon test of OLS } \\
\text { consistency ( } p \text { value) }\end{array}$ & & $89.9(0.0000)$ & $93.0(0.0000)$ \\
\hline $\begin{array}{l}F \text {-test of joint significance of fixed effects } \\
\quad(p \text { value })\end{array}$ & $1.6 \mathrm{e}+05(0.0000)$ & $50,030(0.0000)$ & 49,977 (0.0000) \\
\hline HRW likelihood test ( $p$ value) & & $5.46(0.02)$ & $5.30(0.02)$ \\
\hline$J$-test ( $p$ value $)$ & & $0.36(0.55)$ & \\
\hline Number of observations & 3,605 & 3,605 & 3,605 \\
\hline
\end{tabular}

Dependent variable: waste quantity (kg per inhabitant per year); $t$-values in parentheses. Municipal characteristics (see text) and municipal and year fixed effects included

estimates. User fees for unsorted waste appear to be exogenous. However, for biodegradable waste, the Davidson-MacKinnon test rejects the use of OLS. Here, the price seems to be endogenous.

Including fixed effects at the local level has perhaps removed any price endogeneity for unsorted waste that may have existed. If, e.g., endogeneity arises because municipalities which generate relatively great amounts of garbage are more likely to adopt a UBP program, including fixed effects may control for this. On the other hand, the limited difference between our OLS and our Tobit estimates could be the result of using invalid instruments. Therefore, we will discuss instrument validity at some depth.

A valid instrument is both relevant and exogenous. In our case, this means our instruments must have a strong enough influence on user fees, but no (direct) influence on garbage quantities. Instrument relevance may be assessed using the first stage $F$-statistic of joint significance of the instruments. As a rule of thumb, this statistic should at least equal ten. Since we cannot trust the standard errors of the first stage Tobit estimates, we require the $F$-statistic to be a bit higher, and we also look at the $F$-statistics associated to the OLS estimates. For unsorted waste, the $F$-statistics (Tobit estimation 27; OLS 33, Table 4) are substantially higher than ten. A more formal test of instrument relevance is the likelihood ratio test proposed by Hall et al. (1996), hereafter HRW. ${ }^{18}$ This

18 Davis and Kim (2002) present a convenient way of calculating the HRW test statistic. 
test also rejects the null hypothesis that instruments are not relevant ( $p=0.02$; Table 5). The first-stage $F$-statistics of the biodegradable waste regression are 18 (Tobit) and 26 (OLS; Table 4), and the HRW likelihood ratio test rejects the null hypothesis that instruments are not relevant ( $p=0.02$; Table 5). Based on these results, our instruments seem strong, but the fact that the Tobit standard errors are biased makes it difficult to be sure, especially in the case of biodegradable waste, where $F$-statistics are lower than those for the unsorted waste case. Since instrument weakness may result in misleading estimates, we repeat the IV estimation for biodegradable waste with only $\mathrm{WP}_{i t-1}$ as an instrument. The first stage $F$-statistics now are 29 (Tobit) and 51 (OLS) (Table 4, last column), while the HRW-test still rejects the null hypothesis that instrument is not relevant (Table 5, column 3). These results seem to rule out the weak instrument problem, and the coefficient of $\mathrm{P}_{i t}$ in the waste equation is virtually the same as with both instruments (Table 5, column 3).

The second condition for an instrument to be valid is exogeneity. According to Hansen's $J$-test of overidentifying restrictions, we cannot reject the null hypothesis that all instruments are exogenous, so the instruments can safely be excluded from the second stage regression ( $p$ value 0.20 for unsorted waste and 0.55 for biodegradable waste; Table 5). It may not be surprising that ideology has no direct effect on garbage quantities. However, a direct effect of $\mathrm{WP}_{i t-1}$ on garbage quantities would have been intuitively plausible: households facing a unit fee may be tempted to place their bags at the curbside in a nearby jurisdiction without user fees, or dump their garbage in the bins of relatives or friends who do not face unit costs. Therefore, we look a bit more closely at this possibility, using a refutability test.

In order to do this, we identify a sample of municipalities for which UBP is not a serious option. For this group, the coefficient of $\mathrm{WP}_{i t-1}$ in the garbage regression may be interpreted as the direct effect of neighbors' price, whereas the coefficient for the group of other municipalities reflects both the direct and the indirect effect (through $P_{i t}$ ) (Altonji et al. 2005). For the instrument to be valid, the coefficient for the group for which UBP is not a serious option must be zero. A positive coefficient points to waste tourism. Densely populated municipalities provide a useful sample. ${ }^{19}$ In this sample, only $0.5 \%$ use UBP for biodegradable waste and $6 \%$ for unsorted waste, against $20 \%$ for biodegradable waste and $25 \%$ for unsorted waste in other municipalities. In densely populated municipalities, social cohesion is often thought to be too low to prevent illegal dumping. Often, these municipalities are surrounded by suburban municipalities applying UBP. As it turns out, the coefficients of $\mathrm{WP}_{i t-1}$ are very low and completely insignificant in the densely populated sample ( -6 ( $t$-value -0.08$)$ for unsorted waste, and $0.1(0.00)$ for biodegradable waste), while they are both high and significant in the sample of municipalities which are not densely populated $[-180(-4.0)$ for unsorted waste, and $-252(-8.1)$ for biodegradable waste]. ${ }^{20}$ We conclude that waste tourism does not seem to exist on any significant scale. This outcome lends additional credibility to our assumption that $\mathrm{WP}_{i t-1}$ is a valid instrument.

We conclude that the hypothesis that our instruments are valid has not been rejected. User fees are exogenous for unsorted waste, but endogenous for biodegradable waste. Therefore,

19 Although densely populated municipalities often have a large population, this is not always the case. Conversely, municipalities with many inhabitants may consist of a large number of villages and not be densely populated. As a definition of dense population we use addresses $/ \mathrm{km}^{2}>1,500$ (source: Statistics Netherlands). 20 Dependent variable: waste quantity (kg per inhabitant per year). Year effects, municipal fixed effects and municipal characteristics included. OLS estimates. 
Table 6 The effect of user fees on garbage quantities

\begin{tabular}{llll}
\hline Municipal fixed effects & 1 & 2 & 3 \\
& No & Yes & Yes \\
\hline $\begin{array}{l}\text { Unsorted waste } \\
P_{i t} \text { unsorted waste }\end{array}$ & $-433(-15.9)$ & $-262(-11.1)$ & $-261(-3.7)$ \\
$P_{i t}$ biodegradable waste & & & $11(0.1)$ \\
$F_{i t}$ (introduction UBP) & & & $-37(-1.9)$ \\
Adj. $R^{2}$ & 0.67 & 0.93 & 0.93 \\
$F$-test of joint significance & & $11,846(0.0000)$ & $33,499(0.0000)$ \\
$\quad$ of fixed effects $(p$ value) & & 3,590 & 3,590 \\
Number of observations & 3,590 & & $-456(-3.2)$ \\
$P_{i t}$ biodegradable waste & & $-462(-9.3)$ & $-2(-0.0)$ \\
$P_{i t}$ unsorted waste & $-453(-18.5)$ & & $150(1.0)$ \\
$F_{i t}$ (introduction UBP) & & & $33,432(0.0000)$ \\
$\begin{array}{l}\text { Adj. } R^{2} \\
F \text {-test of joint significance } \\
\text { of fixed effects }(p \text { value })\end{array}$ & & 0.96 & 3,605 \\
Number of observations & 0.76 & $50,030(0.0000)$ & \\
\hline
\end{tabular}

Dependent variable: waste quantity (kg per inhabitant per year). Unsorted waste: OLS estimates, except column 4, where $P_{i t}$ for biodegradable waste is instrumented. Biodegradable waste: IV estimates; $P_{i t}$ for biodegradable waste is instrumented with $\mathrm{WP}_{i t-1}$ and ideology as instruments. $T$-values in parentheses. Year effects and municipal characteristics included (see text)

we will use the IV approach to study the effect of user fees on biodegradable waste quantities, and OLS for unsorted waste.

\section{The Effects of User Fees on Garbage Quantities}

The upper panel of Table 6 summarizes our results concerning the effect of user fees on unsorted garbage quantities, estimated by OLS. Column 1 contains the estimate without fixed effects, column 2 the estimate with municipal fixed effects (equal to that in Table 5, column 1). Failure to include fixed effects leads to a price coefficient that is significantly more negative: -433 instead of -262 . An $F$-test confirms that the fixed effects are highly significant. $^{21}$

The lower panel of Table 6 summarizes our results concerning biodegradable waste, estimated using instrumental variables. Here, the inclusion of fixed effects does not seem to affect the coefficient of the price variable, although the $t$-value is much higher without fixed effects. Still, the fixed effects are highly significant.

Recall that (2) includes the unit price of unsorted waste in the demand function for biodegradable garbage disposal, and vice versa. Column 3 of Table 6 shows that the unit prices for the alternative waste types can safely be dropped from the regressions, however: they turn

21 Dijkgraaf and Gradus (2004, 2009) also used fixed effects, but at the province level, not at the municipal level. However, we find that using province fixed effects still strongly inflates the coefficient. In fact, results with province fixed effects are not very different from results without any fixed effects (price coefficient of $-388, p$ value -14.4 ; not reported in the Table). 
Table 7 Sensitivity analysis

Coefficient of $P_{i t}$

\begin{tabular}{ll}
\hline Unsorted waste (OLS estimates) & \\
Standard assumptions (taken from Table 6, column 2) & $-262(-11.1)$ \\
1 kg equals 51 instead of 7.5 & $-364(-12.3)$ \\
1 kg equals 101 instead of 7.5 & $-197(-10.6)$ \\
User fee set at zero in municipalities where first 18 bins are free of charge & $-254(-10.4)$ \\
Subscription system municipalities included; fee set to zero & $-259(-11.1)$ \\
Subscription system municipalities included; fee at marginal cost of larger bin & $-246(-10.5)$ \\
Household weights instead of individual weights & $-264(-10.7)$ \\
Unweighted regression & $-251(-13.6)$ \\
Biodegradable waste (IV estimates) & \\
Standard assumptions (taken from Table 6, column 2) & $-462(-9.3)$ \\
1 kg equals 31 instead of 3.8 & $-488(-7.3)$ \\
1 kg equals 51 instead of 3.8 & $-414(-12.7)$ \\
User fee set at zero in municipalities where first 18 bins are free of charge & $-467(-8.9)$ \\
Subscription system municipalities included; fee set to zero & $-467(-9.6)$ \\
Subscription system municipalities included; fee at marginal cost of larger bin & $-419(-8.7)$ \\
Household weights instead of individual weights & $-454(-9.0)$ \\
Unweighted regression & $-492(-12.0)$ \\
Distance-based spatial weights matrix instead of contiguity-based matrix &
\end{tabular}

Dependent variable: waste quantity ( $\mathrm{kg}$ per inhabitant per year). $T$-values in parentheses. Municipal characteristics (see text) and municipal and year fixed effects included. Biodegradable waste: IV estimates with $\mathrm{WP}_{i t-1}$ and ideology as instruments

${ }^{a}$ Weighted average of unit prices in jurisdictions within a radius of $25 \mathrm{~km}$ (see Fig. 1) used as an instrument, where inverse distances were used as weights

out to be completely insignificant ( $t$-values 0.0 and 0.1 , respectively). Thus, households do not seem to react to unit-based pricing by discarding waste in the wrong type of bin or bag.

We also test whether the introduction of UBP has an independent effect on waste quantities. We do this by introducing dummies $\left(F_{\text {uit }}\right.$ and $F_{\text {bit }}$ in (2)) which take the value one if UBP is introduced, and zero otherwise. ${ }^{22}$ Linderhof et al. (2001) found long-run elasticities that are slightly higher than short-run elasticities. In contrast to their result, we find that the introduction of UBP has a small but significant negative effect on unsorted waste quantities (Table 6, column 3). The short run effect of UBP exceeds the long run effect by a small margin. For biodegradable waste, we found no significant effect of UBP introduction. Of course, this does not mean that no temporary introduction effect exists; it only means that any such effect is too short-lived to show up in annual data.

As described above, our analysis rests on several assumptions regarding waste prices and spatial policy interaction of user fees. Sensitivity analysis shows that the effect of different assumptions on our conclusions is limited (Table 7). We conclude that our results are not very sensitive to the assumptions we have made. Price coefficients do depend on assumptions, but do not change dramatically when different assumptions are chosen.

22 More precisely, for biodegradable waste the dummy takes the value one if the fitted value of the user fee from the first stage Tobit regression is positive for year $t$ and zero for year $t-1$. For unsorted waste we use actual user fees to generate the introduction dummy. 


\section{Effects of Different UBP Programs}

So far, we have not made a distinction between different UBP systems. It is an interesting question whether different UBP programs have different effects on garbage quantities. Households facing a price per kilogram may react differently than households facing a price per bin.

We have found that user fees for biodegradable waste are endogenous. Unfortunately, we are unable to instrument unit prices for different programs separately. For biodegradable waste we use, as before, the fitted values from the first stage Tobit estimation of the unit price, and multiply these with dummies indicating whether a certain UBP system is used, in order to derive instrumented prices for different UBP programs. Thus, we instrument price, but not UBP system. We feel that the fact that municipalities with the same UBP program are to a large extent grouped together geographically (Fig. 1) lends some credibility to this approach, because this suggests that policy interaction (not waste tourism) may well be the driving force behind program choice.

Table 8 shows that the coefficients for separate UBP systems do indeed differ from each other. ${ }^{23}$ Surprisingly, for biodegradable waste, the bag system has no significant price effect. This is probably due to insufficient variation in the number of municipalities involved ( 9 in 1998; 5 in 2006).

The coefficients summarized in Table 8 allow us to calculate price elasticities. The average user fee in municipalities with a UBP program is 0.18 euro for unsorted waste and 0.12 euro for biodegradable waste (Table 3 ). Measured at this point, the price elasticity of demand is -0.32 for unsorted waste and -0.87 for biodegradable waste. ${ }^{24}$ These elasticities may be used to predict the effect of a price change in municipalities which already have user charges. The arc elasticity associated with a price change from zero to the average values (in UBP jurisdictions) of 0.18 euro for unsorted waste and 0.12 euro for biodegradable waste are -0.11 and -0.37 , respectively. ${ }^{25}$ These elasticities may help predict the price effect from the introduction of user fees. However, as elasticities can be highly sensitive to the point selected along the demand curve, a perhaps clearer indicator of the effect of UBP introduction is the garbage reduction at the average user fee. This is indicated in Table 8.

For unsorted waste, the weight system has the greatest price effect, reducing garbage quantities by $39 \%$, followed by the bag system (28\%) and the bin system (21\%). This is as we expected. The bag program and the bin program, being volume-based, provide households with an incentive to reduce waste volumes. This may be done by reducing weight, but also by compressing garbage. Therefore, a volume-based program may be expected to have less impact on garbage weights than a weight-based system. We find that the effect of the weight-based system is almost twice that of volume-based systems. Of the two volume-based systems, the bin system allows more compression, as bags are liable to rupture when the pressure becomes too high. This may explain why we find a stronger effect for the bag system than for the bin system. Our results for unsorted waste differ from those of Dijkgraaf and Gradus (2009), who found that the weight system and the bag

23 We also estimated the coefficients for the subscription system, using the marginal cost of a larger or extra bin as the user fee. For both unsorted and biodegradable waste, these proved to be insignificant.

24 For unsorted waste, this is calculated as 0.18 (average price for UBP jurisdictions) / 149 (average quantity for UBP jurisdictions) $\times-262$ (price coefficient, Table 6, column 2). For biodegradable waste, it is calculated in a similar fashion.

25 This is calculated in the same way as the point elasticity at a price of $P / 2$. 
Table 8 Results for different UBP systems

\begin{tabular}{|c|c|c|c|c|c|}
\hline & $\begin{array}{l}\text { Coefficient of } \\
\text { price variable } \\
(t \text {-value })\end{array}$ & $\begin{array}{l}\text { Point } \\
\text { elasticity }\end{array}$ & $\begin{array}{l}\text { Arc } \\
\text { elasticity }\end{array}$ & $\begin{array}{l}\text { Garbage } \\
\text { reduction at } \\
\text { average user fee }\end{array}$ & $\begin{array}{l}\text { Garbage } \\
\text { reduction per } \\
\$ 1 \text { user fee }\end{array}$ \\
\hline \multicolumn{6}{|l|}{ Unsorted waste } \\
\hline Total UBP & $-262(-11.1)$ & -0.32 & -0.11 & $24 \%$ & 1.66 \\
\hline Weight system & $-457(-11.9)$ & -0.65 & -0.22 & $39 \%$ & 2.89 \\
\hline Bag system & $-376(-11.7)$ & -0.39 & -0.13 & $28 \%$ & 2.38 \\
\hline Bin system & $-214(-9.4)$ & -0.26 & -0.10 & $21 \%$ & 1.35 \\
\hline Weight/bin system & $-312(-6.9)$ & -0.46 & -0.16 & $31 \%$ & 1.98 \\
\hline Adj. $R^{2}$ & 0.93 & & & & \\
\hline Number of observations & 3,590 & & & & \\
\hline \multicolumn{6}{|l|}{ Biodegradable waste } \\
\hline Total UBP & $-462(-9.3)$ & -0.87 & -0.37 & $46 \%$ & 2.92 \\
\hline Weight system & $-333(-8.7)$ & -1.04 & -0.42 & $51 \%$ & 2.11 \\
\hline Bag system & $-67(-0.2)$ & -0.09 & -0.03 & $8 \%$ & 0.43 \\
\hline Bin system & $-530(-10.1)$ & -0.77 & -0.35 & $43 \%$ & 3.36 \\
\hline Weight/bin system & $-376(-9.0)$ & -1.77 & -0.59 & $64 \%$ & 2.38 \\
\hline Adj. $R^{2}$ & 0.96 & & & & \\
\hline Number of observations & 3,605 & & & & \\
\hline
\end{tabular}

Coefficient for total UBP are taken from Table 6, column 2; coefficients for different UBP programs were derived from a regression with waste quantity (kg per inhabitant per year) as dependent variable. Year effects, municipal fixed effects and municipal characteristics included (see text). Unsorted waste: OLS estimates. Biodegradable waste: IV estimates (see text)

${ }^{a}$ User fee $\$ 1$ per 30 gallon. Garbage reduction in pounds per household per week. One household is assumed to have 2.26 members (average household size in 2006; Statistics Netherlands). In the period under study, the value of one euro in US dollars was in the range [0.9, 1.26]. For simplicity, we used $\$ 1=1$ euro. This column is included to facilitate comparison with Kinnaman (2006, Table 3)

system have a similar impact. ${ }^{26}$ The reduction under the combined weight/bin system for unsorted waste equals the average of the reduction under the weight system and under the bin system.

For biodegradable waste, the effect of UBP under the weight system (a 51\% reduction) is bigger than that under the bin system (43\%). As reported, the price effect for the bag system is not significant for biodegradable waste. For the combined weight/bin system, the effect is rather high, but this system is rarely employed. The price response for biodegradable waste is approximately twice that for unsorted waste. This may be due to the fact that an alternative for curbside collection (home waste composting) is more easily available for this type of waste.

In order to facilitate comparison of our results with those of earlier studies, we also calculated the garbage reduction in pounds per $\$ 1$ user fee (Table 8). Kinnaman (2006) presents results of earlier studies. Our estimates, 1.66 for unsorted waste and 2.92 for biodegradable waste, are closest to the 1.92 estimated by Fullerton and Kinnaman (1996). Remarkably, all other previous estimates are substantially higher, ranging from 5.60 to 22.89 .

26 Dijkgraaf and Gradus (2009) do not use user fee data, but rather dummies for different UBP programs. Effectively, this assumes that user fees are the same in every municipality, while in fact these differ considerably (see Table 3). 
Table 9 Effects of user fees for unsorted waste on recycling

\begin{tabular}{lllll}
\hline & Total recycling & Paper & Glass & Textiles \\
\hline$P_{i t}$ unsorted waste & $46.5(5.1)$ & $33.8(5.5)$ & $10.6(3.8)$ & $1.8(1.9)$ \\
Adj. $R^{2}$ & 0.89 & 0.86 & 0.75 & 0.72 \\
Number of observations & 3,115 & 3,549 & 3,586 & 3,156 \\
Weight system & $54.1(2.9)$ & $35.8(2.5)$ & $14.5(6.3)$ & $1.0(0.3)$ \\
Bag system & $68.3(1.9)$ & $44.2(1.9)$ & $23.6(3.0)$ & $0.8(0.2)$ \\
Bin system & $42.0(4.4)$ & $32.0(4.7)$ & $7.9(2.7)$ & $2.5(2.8)$ \\
Weight/bin system & $52.6(2.8)$ & $37.1(2.4)$ & $17.1(3.0)$ & $-3.6(-1.0)$ \\
Adj. $R^{2}$ & 0.89 & 0.86 & 0.75 & 0.72 \\
Number of observations & 3,115 & 3,549 & 3,586 & 3,156 \\
\hline
\end{tabular}

Dependent variable: quantity of recycled material (kg per inhabitant per year). $T$-values in parentheses. Municipal characteristics (see text) and municipal and year fixed effects included. OLS estimates

\section{Behavioral Effects, Recycling, and Welfare Gain}

An interesting question is how waste quantities are reduced as a result of UBP. For biodegradable waste, obvious alternatives are leaving garden waste in the garden (e.g., after shredding it), and home composting of garden and kitchen garbage. Indeed, there is a lot of anecdotic evidence that the use of compost vats increases after municipalities introduce a UBP program. Unfortunately, we do not have data to analyze the effect of UBP systems on alternative disposal methods for biodegradable waste.

For a fraction of unsorted waste, an alternative exists in the form of drop-off facilities or curbside collection of recyclable waste (glass, paper, textiles). There is no charge for discarding recyclable waste in these manners. Results of earlier studies of the effect of user fees on recycling differ: Fullerton and Kinnaman (1996), Kinnaman and Fullerton (2000) and Jenkins et al. (2003) found no significant effect, while Hong (1999), Callan and Thomas (2006), Kipperberg (2007) and Usui (2008) conclude that user fees increase recycling. Our dataset includes volumes of recyclable waste, from both drop-off facilities and curbside collection. Table 9 shows that the unit price for unsorted waste has a significant and positive effect on quantities recycled. The coefficient of the unit price for unsorted waste in a regression of total recyclable waste equals 47 (5.1). The price coefficient differs for different UBP systems, but these differences are not statistically significant. The implied cross-price arc elasticity is 0.04 . Most of the effect is due to an increase in paper recycling (coefficient 34) and glass recycling (coefficient 11). Textiles recycling plays a minor role.

These results suggest that only about $18 \%(47 / 262)^{27}$ of the reduction in unsorted waste quantities is due to better recycling. What about the rest? We found no evidence of waste tourism (Sect.5). Illegal dumping may account for part of the missing garbage, but if this was a serious problem, one would expect many municipalities to abolish user fees. This has not happened. ${ }^{28}$ Thus, there is no evidence of municipalities becoming disappointed about the effects of UBP programs.

27 The price coefficient for unsorted waste equals -262 (Table 6, column 2).

28 Only five municipalities stopped applying user charges for unsorted waste in 1997-2006. Of these, one re-introduced user charges after 2 years, and all the others dropped user fees in the year they were merged with municipalities without user charges. After municipalities are merged, the new jurisdiction must use a uniform pricing scheme. Mergers often generate discontent among parts of the population which are opposed 
Table 10 Estimated deadweight loss of not using UBP and administrative costs of operating a UBP program (unsorted waste; euros per person per year)

Source administrative costs: KPMG (1997), converted to 2006 euros

\begin{tabular}{lll}
\hline & Deadweight loss & $\begin{array}{l}\text { Administrative } \\
\text { costs of UBP }\end{array}$ \\
\hline Total UBP & 3.2 & NA \\
Weight system & 5.6 & 7.9 \\
Bag system & 4.6 & 3.7 \\
Bin system & 2.6 & 4.9 \\
Weight/bin system & 3.8 & NA \\
\hline
\end{tabular}

Alternatively, households might reduce the amount of garbage they generate by adjusting their purchasing habits, but the scope to do this seems limited. Clearly, further research is needed to locate the "missing" garbage.

Our estimation results can be used to roughly estimate the welfare gains of UBP. Social marginal costs of incineration, the most common form of disposal for unsorted waste in the Netherlands, are estimated to be 111 euros per metric ton. ${ }^{29}$ An estimate of the social costs of composting, the treatment of choice for biodegradable waste, is not available. Adding 45 euros per ton as an educated guess of the marginal social costs of waste collection, ${ }^{30}$ total social costs per ton of unsorted waste may roughly be estimated at 156 euros. Thus, the optimal user fee is 0.16 euro per kilo. Interestingly, this is not much different from the average user fee (0.18 euro, Table 3$)$. Introducing UBP at this optimal unit price is estimated to reduce unsorted waste quantities by $41 \mathrm{~kg}$ on average (the relevant price coefficient being -262, Table 8). Assuming a linear demand curve, the size of the deadweight-loss triangle resulting from a marginal price of zero equals 3.2 euros per inhabitant per year $(41 \times 0.16 / 2)$. The corresponding estimates for the different pricing programs are listed in Table 10. The estimated welfare gains of UBP for unsorted waste have the same order of magnitude as the best available estimates of the administrative costs of operating UBP programs, based on data from 1997 (Table 10).

Administrative costs may have come down somewhat since 1997, and our estimates of the welfare gains are admittedly rough. Still, it is difficult to envisage circumstances where unit pricing will generate substantial net welfare gains. That is, if we assume there are no other benefits of UBP. It could be argued, however, that UBP is more equitable than a flat rate. A flat rate makes garbage collection expensive for small households and for environmentally friendly people. Letting households pay according to use may appeal to some sense of justice. Perhaps that is one of the reasons local governments introduce UBP.

\section{Conclusions}

We estimate the effects of unit-based waste prices on household waste quantities and recycling, using a unique 10-year dataset of annual waste quantities and prices for all 458 Dutch

\section{Footnote 28 continued}

to the merger. Moreover, mergers keep the local administration busy for quite some time. Therefore, this may not be an opportune time to introduce user fees in parts of the newly formed jurisdiction. Ten municipalities stopped applying user fees for biodegradable waste. Of these, five have since re-introduced user fees, while, again, the others all dropped user fees in the year they were merged with municipalities without user fees.

29 Dijkgraaf and Vollebergh (2004), converted to 2006 prices.

30 Waste disposal accounts for $50 \%$ of total waste costs incurred by municipalities, while waste collection accounts for $40 \%$ (Senternovem 2006). We further assume that a garbage reduction of $10 \%$ yields a collection cost reduction of $5 \%$. 
municipalities. We allow for the fact that the unit price may be endogenous, e.g., because municipalities with high waste quantities could be more likely to introduce unit-based pricing as they stand to gain more from a waste reduction. To the best of our knowledge, our study is the first in this field to apply a differences-in-differences approach. We include fixed effects at the local level.

Our main conclusion is that including fixed effects at the municipality level is indeed important. For unsorted waste, failure to include fixed effects inflates the price coefficient by $65 \%$. User fees turn out not to be endogenous, so that we may use OLS estimates for unsorted waste. The inclusion of fixed effects may possibly mitigate any endogeneity problem that might have existed. For biodegradable waste, on the other hand, non-inclusion of fixed effects does not have a significant effect on outcomes. Here, we find that user fees are endogenous. Therefore, we rely on IV estimates for biodegradable waste.

We estimate a garbage reduction at the average user fee of $24 \%$ for unsorted waste and of $46 \%$ for biodegradable waste. For unsorted waste, the weight system has the greatest price effect, reducing garbage quantities by $39 \%$, followed by the bag system $(28 \%)$ and the bin system $(21 \%)$. For biodegradable waste, the effect of the weight system (a 51\% reduction) is bigger than that of the bin system (43\%). The price response for biodegradable waste is approximately twice that for unsorted waste. This may be due to the fact that an alternative for curbside collection (home waste composting) is more easily available for this type of waste.

In order to facilitate comparison of our results with those of earlier studies, we also calculated the garbage reduction in pounds per $\$ 1$ user fee. Our estimates, 1.66 for unsorted waste and 2.92 for biodegradable waste, are closest to the 1.92 estimated by Fullerton and Kinnaman (1996). Remarkably, all other previous estimates are substantially higher, ranging from 5.60 to 22.89. Thus, our approach and our extensive data set improve our understanding of the effects of UBP by suggesting that the effect on household waste quantities is not as large as previously estimated.

Unit pricing increases recycling, especially of paper. Differences in the effects of various pricing schemes on recycling are not statistically significant. It is unclear exactly how garbage quantities are reduced. Increased recycling explains only about one fifth of the reduction of unsorted waste. We do not find evidence of garbage tourism. There is no evidence that municipalities abandon user fees because the results are unsatisfactory, which we would expect if illegal dumping were a problem. For biodegradable waste, easy alternatives exist (e.g., home composting), but reducing unsorted waste seems more difficult. More research is needed here.

Based on our estimations, it is uncertain whether UBP yields any net welfare gains. The efficiency gains derived from the elimination of the excess burden associated with a unit price of zero are of the same order of magnitude as the administrative costs associated with UBP. Perhaps the fact that UBP is more equitable, in the sense that households producing little waste do not have to pay the same amount as households that produce a lot of garbage, is a reason for some communities to introduce UBP.

Acknowledgements The authors thank Elbert Dijkgraaf, Raymond Gradus and two anonymous referees for their helpful comments, and Simon Boddeüs and Mark Kruidhof for their assistance in obtaining the data.

Open Access This article is distributed under the terms of the Creative Commons Attribution Noncommercial License which permits any noncommercial use, distribution, and reproduction in any medium, provided the original author(s) and source are credited. 


\section{References}

Allers MA, Elhorst JP (2005) Tax mimicking and yardstick competition among local governments in the Netherlands. Int Tax Public Finan 12: 493-513

Altonji JG, Elder TE, Taber CR (2005) An evaluation of instrumental variable strategies for estimating the effects of catholic schooling. J Human Resour XL: 791-821

Ashworth J, Geys B, Heyndels B (2006) Determinants of tax innovation: the case of environmental taxes in Flemish municipalities. Eur J Polit Econ 22: 223-247

Baltagi BH (2005) Econometric analysis of panel data. John Wiley, Chichester

Berry FS, Berry WD (1992) Tax innovation in the states: capitalizing on political opportunity. Am J Polit Sci 36: 715-742

Bertrand M, Duflo E, Mullainathan S (2004) How much should we trust differences in differences estimates? Q J Econ 119: 249-275

Besley T, Case A (2000) Unnatural experiments? Estimating the incidence of endogenous policies. Econ J 110: F672-F694

Brueckner JK (2003) Strategic interaction among governments: an overview of empirical studies. Int Reg Sci Rev 26: 175-188

Callan SJ, Thomas JM (1999) Adopting a unit pricing system for municipal solid waste: policy and socioeconomic determinants. Environ Resour Econ 14: 503-518

Callan SJ, Thomas JM (2006) Analyzing demand for disposal and recycling services: a systems approach. East Econ J 32:221-240

Davidson R, MacKinnon J (1993) Estimation and inference in econometrics. Oxford University Press, New York

Davis GC, Kim ST (2002) Measuring instrument relevance in the single endogenous regressor-multiple instrument case: a simplifying procedure. Econ Lett 74: 321-325

Dijkgraaf E, Gradus RHJM (2004) Cost savings in unit-based pricing of household waste: the case of The Netherlands. Resour Energy Econ 26: 353-371

Dijkgraaf E, Gradus R (2008) Per-unit garbage charges. J Econ Perspect 22: 243-244

Dijkgraaf E, Gradus R (2009) Environmental activism and dynamics of unit-based pricing systems. Resour Energy Econ 31: 13-23

Dijkgraaf E, Vollebergh HRJ (2004) Burn of bury? A social cost comparison of final waste disposal methods. Ecol Econ 50: 233-247

Ferrara I, Missios P (2005) Recycling and waste diversion effectiveness: evidence from Canada. Environ Resour Econ 30: 221-238

Fullerton D, Kinnaman TC (1996) Household responses To pricing garbage by The bag. Am Econ Rev 86: 971-984

Gellynck X, Verhelst P (2007) Assessing instruments for mixed household solid waste collection services in the Flemish region of Belgium. Conserv Recycling 49: 372-387

Greene W (2003) Fixed effects and bias due to the incidental parameters problem in the Tobit model. Econom Rev 23: 125-147

Hall AR, Rudebusch GD, Wilcox DW (1996) Judging instrument relevance in instrumental variables estimation. Int Econ Rev 37: 283-298

Heijnen P (2007) Strategic interactions in environmental economics. Labyrint, Ridderkerk

Hong S (1999) The effects of unit pricing system upon household solid waste management: The Korean experience. J Environ Manage 57:1-10

Hong SH, Adams RM (1999) Household responses to price incentives for recycling: some further evidence. Land Econ 75: 505-514

Jenkins RR (1993) The economics of solid waste reduction. Edward Elgar, Aldershot

Jenkins RR, Martinez SA, Palmer K, Podolsky MJ (2003) The determinants of household recycling: a material-specific analysis of recycling program features and unit pricing. J Environ Econ Manage 45: 294-318

Kinnaman TC (2006) Policy watch: examining the justification for residential recycling. J Econ Perspect 20: 219-232

Kinnaman TC, Fullerton D (2000) Garbage and recycling with endogenous local policy. J Urban Econ 48: 419-442

Kinnaman T (2008) Response from Thomas Kinnaman. J Econ Perspect 22: 244-245

Kipperberg G (2007) A comparison of household recycling behaviors in Norway and the United States. Environ Resour Econ 36: 215-235

KPMG Bureau voor Economische Argumentatie (1997) Ervaringen met tariefdifferentiatie en huishoudelijk afval. Hoofddorp 
Linderhof V, Kooreman P, Allers M, Wiersma D (2001) Weight-based pricing in the collection of household waste: the Oostzaan case. Resour Energy Econ 23: 359-371

Podolsky MJ, Spiegel M (1998) Municipal waste disposal: unit-pricing and recycling opportunities. Public Works Manage Policy 3: 27-39

Rincke J (2007) Policy diffusion in space and time: the case of charter schools in California school districts. Reg Sci Urban Econ 37: 526-541

Salmon P (1987) Decentralisation as an incentive scheme. Oxf Rev Econ Policy 3: 24-43

Senternovem (2006) De afvalmarkt 2006: overheidsondernemingen en huishoudelijk restafval. Utrecht

Usui T (2008) Estimating the effect of unit-based pricing in the presence of sample selection bias under Japanese recycling law. Ecol Econ 66: 282-288

Van Houtven GL, Morris GE (1999) Household behavior under alternative pay-as-you-throw systems for solid waste disposal. Land Econ 75: 515-537 